\title{
Donated breast milk substitutes and incidence of diarrhoea among infants and young children after the May 2006 earthquake in Yogyakarta and Central Java
}

\author{
David B Hipgrave ${ }^{1, *}$, Fitsum Assefa ${ }^{2}$, Anna Winoto ${ }^{3}$ and Sri Sukotjo ${ }^{3}$ \\ 'United Nations Children's Fund China Country Office, 12 Sanlitun Lu, Beijing 100600, People's Republic of \\ China: ${ }^{2}$ United Nations Children's Fund Zimbabwe Country Office, 6 Fairbridge Avenue Belgravia, Harare, \\ Zimbabwe: ${ }^{3}$ United Nations Children's Fund Indonesia Country Office, Level 10, Wisma Metropolitan II, \\ Jalan Sudirman, Jakarta, Indonesia
}

Submitted 24 January 2010: Accepted 20 September 2010: First published online 23 March 2011

\begin{abstract}
Objective: Distribution of breast milk substitutes (BMS) after the 2006 Yogyakarta earthquake was uncontrolled and widespread. We assessed the magnitude of BMS distribution after the earthquake, its impact on feeding practices and the association between consumption of infant formula and diarrhoea among infants and young children.

Design: One month after the earthquake, caregivers of 831 children aged 0-23 months were surveyed regarding receipt of unsolicited donations of BMS, and on recent child-feeding practices and diarrhoeal illness.

Setting: Community-level survey in an earthquake-affected district.

Subjects: Primary caregivers of surveyed children.

Results: In all, $75 \%$ of households with an infant aged $0-5$ months and $80 \%$ of all households surveyed received donated infant formula; $76 \%$ of all households received commercial porridge and $49 \%$ received powdered milk. Only $32 \%$ of 0-5-month-old infants had consumed formula before the earthquake, but $43 \%$ had in the $24 \mathrm{~h}$ preceding the survey $(P<0 \cdot 001)$. Consumption of all types of BMS was significantly higher among those who received donated commodities, regardless of age $(P<0 \cdot 01)$. One-week diarrhoea incidence among those who received donated infant formula $(25 \cdot 4 \%)$ was higher than among those who did not $(11 \cdot 5 \%$; relative risk $=2 \cdot 12,95 \% \mathrm{CI}=1 \cdot 34,3 \cdot 35)$. The rate of diarrhoea among those aged 12-23 months was around five times the pre-earthquake rate. Conclusions: There were strong associations between receipt of BMS and changes in feeding practices, and between receipt of infant formula and diarrhoea. Uncontrolled distribution of infant formula exacerbates the risk of diarrhoea among infants and young children in emergencies.
\end{abstract}

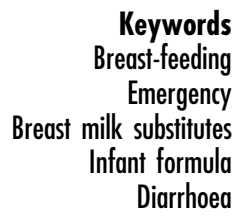

mergency

milk substitutes

Diarrhoea
It is estimated that 219 million people in Indonesia live in an environment in which there is a high risk of natural disasters $^{(1)}$. On 27 May 2006, an earthquake measuring $6 \cdot 2$ on the Richter scale ${ }^{(2)}$ devastated the provinces of Yogyakarta and Central Java, killing about 6000 people, injuring another 40000-60000 and robbing hundreds of thousands of their homes and livelihood ${ }^{(3)}$.

The emergency response to the earthquake was rapid; during the weeks immediately following, we observed humanitarian actors providing large volumes of consumables to affected families. Contrary to the relevant operational guidelines ${ }^{(4)}$ that provide detailed instructions on the procurement, handling and use of donated breast milk substitutes (BMS) such as infant formula, powdered milk and complementary foods, such commodities were widely distributed to families with infants and young children. Many of these products were supplied in bulk, with no instructions to relief workers on targeting, their safe use or screening of recipient families' needs. The channels of distribution included their inclusion in the general ration given to affected households, and handouts at temporary and fixed health facilities and temporary shelters. BMS was portrayed by donors, distributors and the media as providing essential nutrition for infants, and mothers were considered less likely to breast-feed because of stress, injury, pre-occupation with damage to property and loss of privacy $^{(3,5)}$.

Infant and young child feeding (IYCF) practices in Indonesia are far from optimal. Real practices diverge markedly from global recommendations for exclusive 
breast-feeding for the first 6 months of life, followed by continued breast-feeding with appropriate complementary food up to the age of 2 years $^{(6)}$. According to the 2007 Indonesia Demographic and Health Survey (DHS), only $17 \cdot 8 \%$ of infants are still exclusively breast-fed at 4-5 months of age, and $50.7 \%$ of children are given pre-lacteal intake (such as water, infant formula, honey, dates, banana, herbal drinks or other substances ${ }^{(7)}$ ) before commencing to suckle ${ }^{(8)}$. In addition, diarrhoeal illness is common among children aged $<2$ years in Indonesia ${ }^{(8)}$.

Early cessation of exclusive breast-feeding and of any breast-feeding increases under- 5 mortality ${ }^{(9)}$ and susceptibility to infections ${ }^{(10-15)}$, especially in emergency situations $^{(16,17)}$. Although anecdotal information suggests that certain emergency responses have negatively affected breast-feeding practices in various situations ${ }^{(18)}$, there is limited evidence showing the extent or direct impact of the problem. In this context, we report the results of a survey conducted to assess the extent of distribution of BMS and complementary foods after the May 2006 Yogyakarta earthquake, and its association with IYCF practices and diarrhoea incidence among children aged 0-23 months.

\section{Methods}

\section{Study setting}

The survey was conducted in tandem with the registration of pregnancies by local health authorities from 18 to 24 June 2006 in the seven sub-districts most affected by the earthquake in Bantul district, Yogyakarta province. Bantul and adjacent Klaten (in Central Java province) were the districts most affected by the earthquake.

\section{Recruitment of interviewees}

Pregnant women were identified using pre-earthquake registers held at sub-district health centres. Women were sought by survey team members at their residential address or at temporary shelters within their neighbourhood. Women who could not be found locally were not sought elsewhere.

Assuming that pregnancy and the location of pregnant women were chance events, the registration process was also used to randomly identify infants and young children in the surveyed areas. For every second pregnant woman interviewed, the child aged $<2$ years who slept nearest to her was identified, irrespective of whether that child was hers or of a friend, relative or neighbour. If there was more than one child $<2$ years of age in the house, tent or shelter, interviewers were instructed to randomly assess only one of them. Once identified, the child's primary caregiver (mother, grandmother, etc.) was interviewed.

\section{Data collection and survey instrument}

Interviewers for the survey were students from the University of Gajah Mada in Yogyakarta and from non-government organisations, trained by UNICEF and university staff, and supervised by the university's Public Health and Nutrition Department.

The questionnaire was prepared and tested locally, and comprised fifteen simple questions, including eight on IYCF and receipt of donations (see Box 1). If the respondent was not the mother, surveyors were instructed to adapt the questions according to her relationship to the child. Infant feeding status was assessed using 24 hecall $^{(19)}$.

The other seven questions related to vitamin A supplementation, measles vaccination and management of injuries sustained.

\section{Statistical analysis}

The questionnaires were coded, entered, cleaned and analysed using the Statistical Package for the Social Sciences statistical software package version $11 \cdot 0$ (SPSS Inc., Chicago, IL, USA) and OpenEpi freeware (available at www. openepi.com). Data were verified by checking for consistency and range.

The primary outcome variables were the type of BMS donations received, BMS consumption before and after the earthquake and prevalence of diarrhoea in the previous week. Analysis was conducted by the number of infants affected, not by number of episodes. Crude analyses were used to test associations, expressed as twosided probability values.

Children were categorised by age (0-5, 6-11, 6-23 and 12-23 months), and BMS was categorised as infant formula, commercial porridge, powdered milk and blended fortified food. Receipt of baby bottles was also recorded.

Information on diarrhoeal disease rates among children aged 12-23 months and living in Central Java before the earthquake was drawn from a Nutrition and Health Surveillance System maintained by the Indonesian government and Helen Keller International, which recorded data quarterly during the years $1999-2003^{(20)}$.

\section{Results}

\section{Sample characteristics}

A total of 831 primary caregivers of children aged 0-23 months (46\% of the children were girls) agreed to be interviewed; 296 (36\%) children on whom information was sought were aged $0-5$ months and 535 (64\%) were aged 6-23 months. In each sub-district, the number of such children identified was within $4 \%$ of that expected according to pre-earthquake population data, with one exception in which there were $10 \%$ more children than expected, possibly because of movement of displaced persons into that area.

\section{Receipt of breast milk substitutes}

The receipt of different types of BMS by the household of each child surveyed is depicted in Fig. 1, which shows that $80 \%$ received infant formula, $76 \%$ received 
Box 1

Eight survey questions on infant and young child feeding and receipt of donations

1. At this moment, do you breast-feed your child?

2. Have you ever breast-fed your child?

3. Did you stop breast-feeding because of the earthquake?

4. Why did you stop breast-feeding after the earthquake?
1. Breast milk not enough/would not come out
2. Could not breast-feed because of injury
3. Availability of BMS (baby's milk, formula) from donations
4. No private place to breast-feed
5. Others, specify

5. Please list the types of food and drink given to the child in the last $24 \mathrm{~h}$ (initially do not prompt; record all responses given; prompt if item is not mentioned; record frequency of consumption for each)
1. Breast milk
2. Infant formula
3. Powdered milk
4. Commercial porridge
5. MP-ASI
6. Mung bean porridge
7. Biscuit
8. Instant noodles

Times $\ldots$
Times $\ldots$
Times $\ldots$
Times $\ldots$
Times $\ldots$
Times $\ldots$
Times $\ldots$
Times $\ldots$

6. Did you receive donations of any of the following after the earthquake? (initially do not prompt; record all responses given; prompt if item is not mentioned, and again after quickly looking for any obviously donated items)
1. Commercial porridge
2. MP-ASI
3. Infant formula
4. Powdered milk
5. Baby bottle
6. Instant noodles
7. Biscuit
8. Vegetables
9. Fruit
10. Cooking oil
11. Drinking water
12. Stove
13. Others.... specify

7. Before the earthquake did your child ever consume the following?

1. Commercial porridge

2. MP-ASI

3. Infant formula

4. Powdered milk

8. In the last $7 \mathrm{~d}$ did your child have diarrhoea? (loose stools more than three times in $24 \mathrm{~h}$ )
1. Yes, exclusively $\rightarrow$ no. 5

2. Yes, with other drink/food $\rightarrow$ no. 5

3. No

1. Yes 2 No $\rightarrow$ no. 5

1. Yes 2 No $\rightarrow$ no. 5

2. No

1. Yes No

1. Yes No

2. No

$\begin{array}{ll}\text { 1. Yes } & \text { 2. No }\end{array}$

$\begin{array}{ll}\text { 9. Rice } & \text { Times } \ldots \\ \text { 10. Vegetables } & \text { Times } \ldots \\ \text { 11. Fruit } & \text { Times } \ldots \\ \text { 12. Tempe/tofu } & \text { Times ... } \\ \text { 13. Egg } & \text { Times } \ldots \\ \text { 14. Fish } & \text { Times } \ldots \\ \text { 15. Meat } & \text { Times } \ldots \\ \text { 16. Others (list) } & \text { Times ... }\end{array}$

MP-ASI, Makanan Pendamping ASI (a complementary food of blended fortified porridge, available from health centre).

commercial porridge, $49 \%$ received powdered milk and $31 \%$ received blended food. A total of $89 \%$ received either infant formula or powdered milk. In addition, 14\% received baby bottles. Although households with infants aged $<6$ months were around $10 \%$ less likely to have received infant formula than households with older children, 75\% were supplied with it.

\section{Impact of donations on the use of breast milk substitutes}

During the weeks immediately following the earthquake, we observed that infant formula, powdered milk and other BMS were distributed widely and free of charge, in some cases as part of a general ration provided to displaced or affected families (Fig. 1). The rate of exclusive 


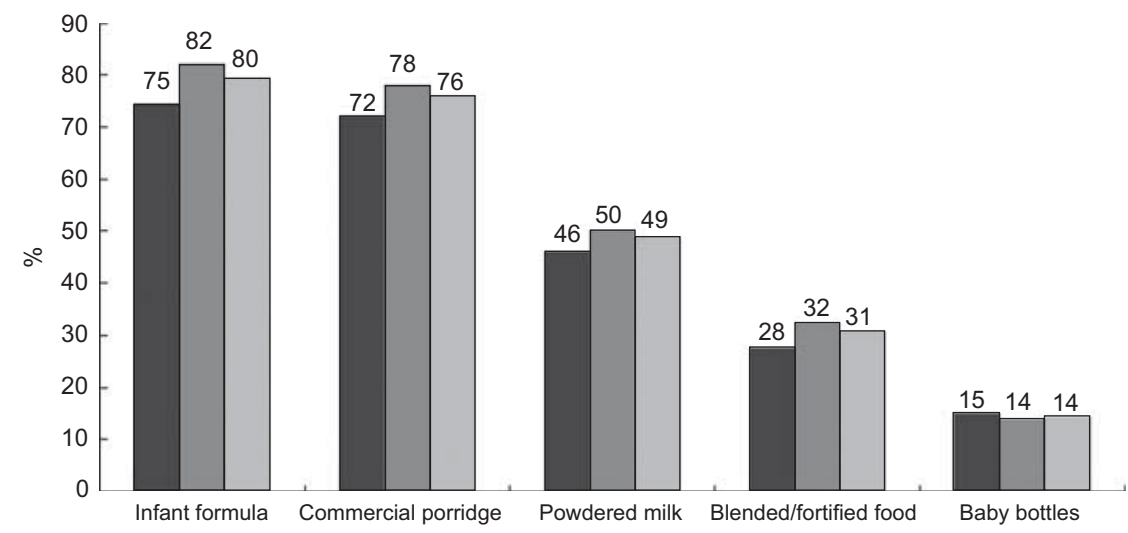

Fig. 1 Household receipt of four varieties of donated breast milk substitutes and baby bottles by age ( $\square, 0-5$ months ( $n 269)$; , 6-23 months ( $n$ 535); , total (0-23 months) ( $n$ 831)

Table 1 Rates of breast-feeding and of diarrhoea according to receipt and consumption of donated infant formula, with corresponding RR and $95 \% \mathrm{Cl}$, by age

\begin{tabular}{|c|c|c|c|c|c|c|c|c|}
\hline & \multicolumn{8}{|c|}{ Age (months) } \\
\hline & \multicolumn{2}{|c|}{$0-5(n 296)^{\star}$} & \multicolumn{2}{|c|}{$6-11(n 258)$} & \multicolumn{2}{|c|}{$12-23(n 277)$} & \multicolumn{2}{|c|}{ Total $(n 831)$} \\
\hline & \multicolumn{2}{|c|}{$\%$} & \multicolumn{2}{|c|}{$\%$} & \multicolumn{2}{|c|}{$\%$} & \multicolumn{2}{|c|}{$\%$} \\
\hline \multicolumn{9}{|c|}{ Breast-feeding during the $24 \mathrm{~h}$ before the survey } \\
\hline Exclusive & \multicolumn{2}{|c|}{33} & \multicolumn{2}{|c|}{$3 \cdot 0$} & \multicolumn{2}{|c|}{3} & \multicolumn{2}{|c|}{14} \\
\hline Mixed & \multicolumn{2}{|c|}{60} & \multicolumn{2}{|c|}{$84 \cdot 5$} & \multicolumn{2}{|c|}{77} & \multicolumn{2}{|c|}{73} \\
\hline \multirow[t]{2}{*}{ None } & \multicolumn{2}{|c|}{7} & \multicolumn{2}{|c|}{$12 \cdot 5$} & \multicolumn{2}{|c|}{20} & \multicolumn{2}{|c|}{13} \\
\hline & $n$ & $\%$ & $n$ & $\%$ & $n$ & $\%$ & $n$ & $\%$ \\
\hline \multicolumn{9}{|c|}{ Diarrhoea during the $7 \mathrm{~d}$ before the survey } \\
\hline \multicolumn{9}{|c|}{ Received infant formula } \\
\hline Yes & 30 & 14 & 60 & 29 & 72 & 33 & 162 & 25 \\
\hline No & 5 & 7 & 8 & 20 & 6 & 12 & 19 & 12 \\
\hline Adjusted RR & \multirow{2}{*}{\multicolumn{2}{|c|}{$\begin{array}{c}2 \cdot 10 \\
0 \cdot 81,5 \cdot 40\end{array}$}} & \multirow{2}{*}{\multicolumn{2}{|c|}{$\begin{array}{c}1 \cdot 32 \\
0 \cdot 66,2 \cdot 65\end{array}$}} & \multirow{2}{*}{\multicolumn{2}{|c|}{$\begin{array}{c}2 \cdot 63 \\
1 \cdot 20,5 \cdot 78\end{array}$}} & \multirow{2}{*}{\multicolumn{2}{|c|}{$\begin{array}{c}2.12 \\
1.34,3.35\end{array}$}} \\
\hline $95 \% \mathrm{Cl}$ & & & & & & & & \\
\hline \multicolumn{9}{|c|}{ Consumed infant formula } \\
\hline Yes & 19 & 15 & 40 & 28 & 49 & 30 & 108 & 25 \\
\hline No & 18 & 11 & 30 & 27 & 32 & 28 & 80 & 20 \\
\hline Adjusted RR & \multirow{2}{*}{\multicolumn{2}{|c|}{$\begin{array}{c}1.39 \\
0.74,2.61\end{array}$}} & \multirow{2}{*}{\multicolumn{2}{|c|}{$\begin{array}{c}1.07 \\
0.70,1.63\end{array}$}} & \multirow{2}{*}{\multicolumn{2}{|c|}{$\begin{array}{c}1.02 \\
0.69,1.48\end{array}$}} & \multirow{2}{*}{\multicolumn{2}{|c|}{$\begin{array}{c}1.23 \\
0.95,1.60\end{array}$}} \\
\hline $95 \% \mathrm{Cl}$ & & & & & & & & \\
\hline
\end{tabular}

$\mathrm{RR}$, relative risk.

*For calculation of percentages, denominators were adjusted for missing data.

breast-feeding in the $24 \mathrm{~h}$ before the survey among infants $<6$ months of age was only $33 \%$, but breast-feeding into the second year of life continued among the majority of infants and young children surveyed (Table 1). However, regarding infant formula intake among infants aged 0-5 months, there was an increase from $32 \%$ having ever consumed it before the earthquake (indicating that precrisis infant feeding in the affected areas was not optimal) to $43 \%$ having done so in the $24 \mathrm{~h}$ before the survey. Increases in previous and recent formula consumption were observed among such infants in both recipient $(37-48 \%, P<0 \cdot 001)$ and non-recipient (18-30\%, $P<0 \cdot 001)$ households.

The mass distribution of unsolicited BMS clearly changed IYCF practices and increased formula feeding in the affected areas. For each of the four commodities assessed, significantly more infants had consumed it in the previous $24 \mathrm{~h}$ if the household had received it than if the household had not $(P<0.01$ for each commodity). Most alarmingly, this also applied to young infants aged $0-5$ months (Fig. 2). Among older infants and young children (aged 6-23 months), $67 \%$ of infants in households receiving donated formula had consumed it in the previous $24 \mathrm{~h}$, compared with $37 \%$ in non-recipient households.

\section{Incidence of diarrboea}

The 1-week incidence of diarrhoea among those who received donations of infant formula $(25 \cdot 4 \%)$ was more than double that of those who did not $(11.5 \%$; relative risk $(\mathrm{RR})=2 \cdot 12,95 \% \mathrm{CI} 1 \cdot 34,3 \cdot 35$; Table 1$)$. Incidence of diarrhoea among infant formula recipients increased with age, and was greater than the incidence of diarrhoea in non-recipients for each age group. This difference was significant for the oldest age group. For each age group, 


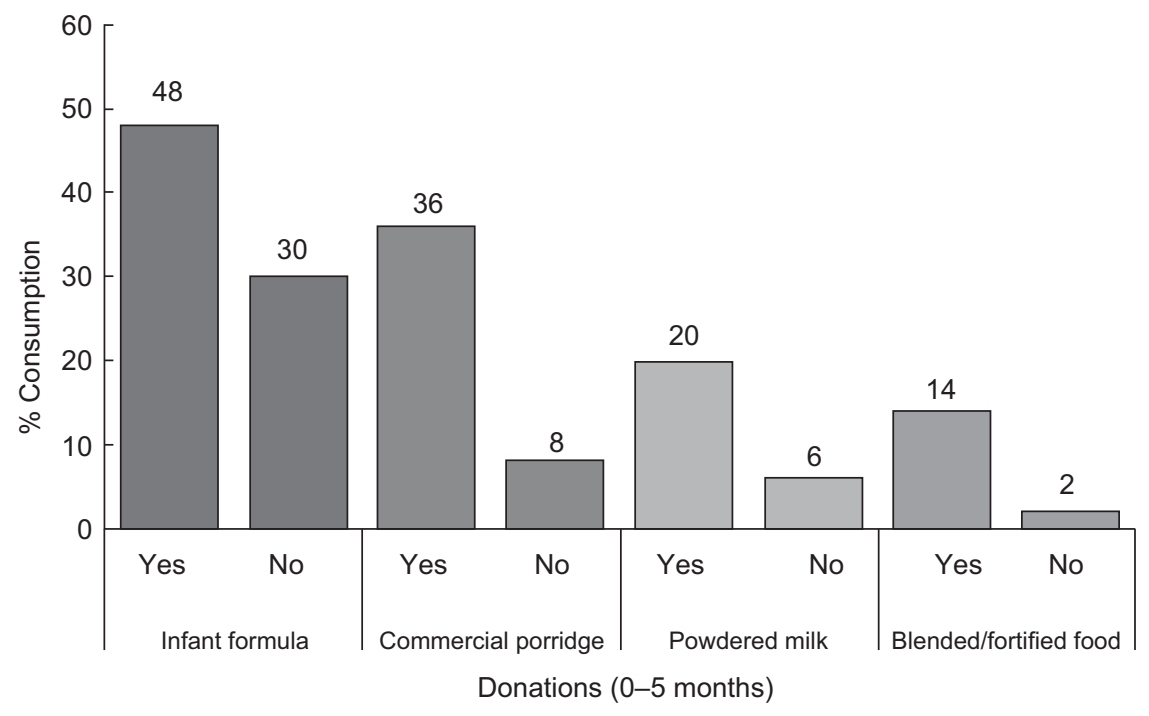

Fig. 2 Consumption of four types of breast milk substitutes by infants aged 0-5 months according to household receipt of donated supplies

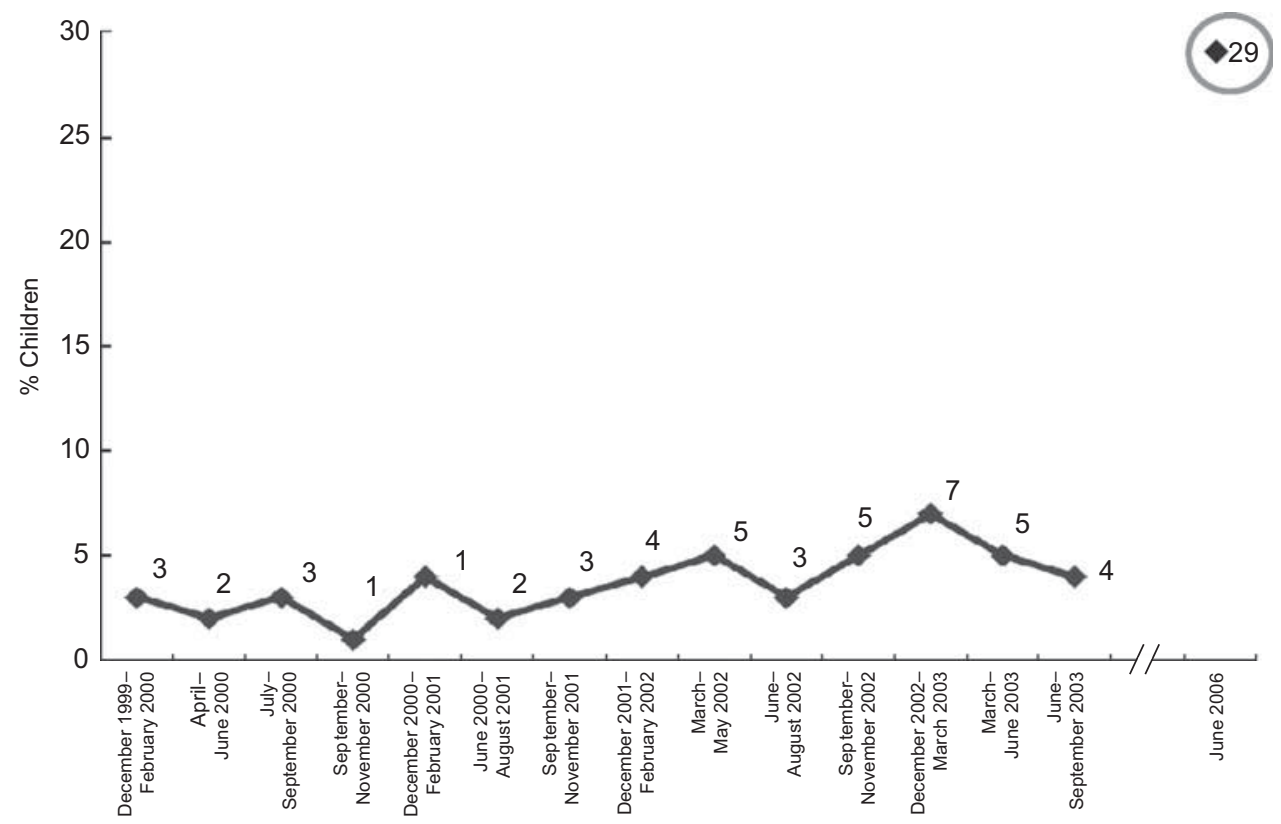

Fig. 3 Seven-day incidence of diarrhoea among children aged 12-23 months in Central Java, December 1999-September 2003, and in Bantul, June 2009 (Source: Data for 1999-2003 are from Central Java. Data were not collected between February and June 2001. The June 2006 observation is from adjacent Bantul)

diarrhoea was also more common among those who had consumed infant formula in the preceding $24 \mathrm{~h}$, but the differences were not significant. For the entire sample, the RR for diarrhoea among children who had consumed infant formula in the $24 \mathrm{~h}$ before the survey was 1.23 (95\% CI 0.95, 1.60).

Data collected before the earthquake enabled a comparison of the overall surveyed incidence of diarrhoea among those aged 12-23 months (29\%) with what was normal in children of the same age in Central Java beforehand (1-7\%).
There was a large increase in the incidence of diarrhoea among those affected by the crisis (Fig. 3) ${ }^{(20)}$.

\section{Distribution of key outcomes by location surveyed}

To enable a comparison of the key survey findings by geographical location, and thus rule out local influences, Table 2 provides the percentages of three key variables assessed in each of the seven surveyed sub-districts. There were no interactions between differences in household receipt or consumption of infant formula and 


\begin{tabular}{|c|c|c|c|c|c|c|c|c|}
\hline & \multicolumn{8}{|c|}{ Sub-district name (and number sampled in each) } \\
\hline & $\begin{array}{c}\text { Bambang } \\
\text { Lipuro }(n 87)\end{array}$ & $\begin{array}{l}\text { Dlingo } \\
(n 73)\end{array}$ & $\begin{array}{l}\text { Imogiri } \\
(n 123)\end{array}$ & $\begin{array}{l}\text { Jetis } \\
(n 130)\end{array}$ & $\begin{array}{c}\text { Piyungan } \\
\text { (n 149) }\end{array}$ & $\begin{array}{l}\text { Pleret } \\
(n \text { 195) }\end{array}$ & $\begin{array}{l}\text { Pundong } \\
(n 74)\end{array}$ & $\begin{array}{c}\text { All } \\
\text { sub-districts }\end{array}$ \\
\hline & $\%$ & $\%$ & $\%$ & $\%$ & $\%$ & $\%$ & $\%$ & $\%$ \\
\hline Household receipt of infant formula & 85 & 57 & 79 & 74 & 89 & 78 & 91 & 80 \\
\hline Consumption of infant formula (all ages) & 59 & 36 & 43 & 62 & 61 & 50 & 44 & 52 \\
\hline One-week diarrhoea incidence (all ages) & 24 & 16 & 20 & 22 & 24 & 22 & 35 & 23 \\
\hline
\end{tabular}

risk of diarrhoea among any of the infants and young children across the seven sub-districts surveyed.

\section{Discussion}

We surveyed the receipt of donated BMS by earthquakeaffected families, as well as IYCF practices and the 1-week incidence of diarrhoea, among infants and young children in Yogyakarta in June 2006, 1 month after it was devastated by an earthquake. We identified a general disregard for recommended practices on IYCF in emergencies $^{(4)}$, with distribution of commodities to affected families being both widespread and unscreened. There appears to have been no attempt to limit the distribution of BMS according to the pre-existing feeding practices of the caregivers surveyed, or to households with older infants, or to those in which infants were no longer being breast-fed but with extra attention given to hygiene in such households. These findings confirm our observation and communications that many agencies active in the relief effort prioritised BMS distribution ${ }^{(21-23)}$, usually without regard to these and other recommended practices.

IYCF practices changed as a result, with consumption of infant formula among all infants aged $<6$ months increasing proportionally by more than a third, including a significant increase in recipient households. These increases may even be underestimates, as $24 \mathrm{~h}$ recall is known to grossly underestimate longer-term consumption of foods other than breast milk ${ }^{(24)}$. We note that the increase was also significant among such infants in nonrecipient households, although numbers were small. Clearly, BMS was easily available to all households and breast-feeding was not being protected in the affected areas. Young infants were also far more likely to consume other commodities if the household had received them. These findings underscore the fragility of good IYCF practices, which, even when it is most important for them to be safe, can easily tip from bad to worse without support from the local health sector and under external influences.

Moreover, we identified increased rates of diarrhoea among children in households receiving infant formula compared with those who did not, and, for those aged 12-23 months, compared with multi-year average rates among same-aged peers in almost the same locality ${ }^{(20)}$. We also found a strong trend towards an association between diarrhoea and consumption of infant formula, despite surveying formula intake only over the preceding $24 \mathrm{~h}$. This association may have been significant if we had surveyed consumption of infant formula during a longer period of time.

Emergency workers and organisations frequently voice concern that indiscriminate distribution of infant formula in emergencies increases rates of formula feeding and diarrhoea. However, we have not identified any similarly documented risks of such distribution in disaster-affected locations, most likely because of the difficulties involved in conducting field surveys during emergency operations. Although our survey can at best be described as a 'quick and dirty' assessment, and causality has not been established, the association between receipt of infant formula and diarrhoeal disease was strong. The receipt of donated commodities and IYCF practices that we observed were not specific to certain sub-districts; there were no outbreaks of diarrhoeal disease in earthquake-affected areas during the weeks preceding the survey and the reports of diarrhoea were not concentrated in certain locations. The high overall 1-week incidence of diarrhoea identified also suggests that all children in surveyed areas were at risk, probably because of lack of clean water and/or poor sanitation. In the 2007 Indonesia DHS, 2-week incidence of diarrhoea among < 5-year-olds in Yogyakarta was only $5 \cdot 4 \%$ and in Central Java $9 \cdot 3 \%{ }^{(9)}$. The receipt of infant formula after the Yogyakarta earthquake was associated with more than double the risk of diarrhoeal illness in young children, thus exacerbating the plight of affected families.

Diarrhoeal disease is, after pneumonia, the second most common cause of death due to infectious disease in young children, accounting for $17 \%$ of deaths among children aged $<5$ years ${ }^{(25)}$. Children in this age group are at particularly high risk of malnutrition, morbidity and mortality in disaster-affected areas ${ }^{(26,27)}$, and it is likely that the risks are maximal in the first 2 years of life. Breastfeeding was highly protective against severe morbidity and mortality during a diarrhoea outbreak predominantly affecting <2-year-olds in Botswana ${ }^{(28)}$; up to $90 \%$ of deaths in emergency situations are due to diarrhoea ${ }^{(16)}$. It is incumbent on agencies and individuals caring for 
infants and young children to provide for their health and nutrition, to protect their safety and avoid causing harm. Clearly, although this includes ensuring their adequate nutrition (and for older infants and young children this includes appropriate food), relief workers also have a responsibility to protect breast-feeding and prevent the risk of diarrhoeal illness due to consumption of unhygienically prepared food and drink, including in nonbreast-fed infants. However, this is not only a water, sanitation and hygiene (WASH) issue. Use of infant formula (even if partial breast-feeding continues) increases the risk of respiratory and gastrointestinal infections, even when WASH standards are not in question ${ }^{(29-31)}$. As shown here, unsolicited donations of BMS change IYCF practices and thus increase the risks of such infections. Formula milk is also nutritionally inferior to breast milk in a variety of ways ${ }^{(31)}$ and emerging data suggest important long-term negative impacts of formula feeding on adult health and nutrition status ${ }^{(32)}$. Thus, from an infectious disease and overall health and nutrition perspective, formula feeding of infants and young children affected by emergencies is risky, regardless of how it is prepared. Children $>6$ months of age should also consume carefully prepared, appropriate food to supplement breast milk (or for non-breast-feeding infants, other milk) according to the relevant guidelines ${ }^{(4,33)}$.

In any emergency, the procurement, management and distribution of BMS, including milk products, bottles and teats, should be strictly based on technical advice that takes into account the attendant risks and impact on longterm practices of recipient mothers, and on the needs of the affected population. It should also comply with the International Code on Marketing of $\mathrm{BMS}^{(34)}$, which was adopted by WHO in 1981. Adherence to this code protects infants and young children from blatant or stealthy attempts to influence their mothers' behaviour, and in emergency situations is especially important for controlling unsolicited donation and distribution of unsuitable products (a form of advertising and, as shown here, behaviour change communication by default).

During the response to the Yogyakarta earthquake, the code and the related Operational Guidance ${ }^{(4)}$ (including a version in Bahasa Indonesia) were ignored. We saw no centralised system to manage and control BMS distribution, and the widely held perspective was that most women in Indonesia use infant formula already, hence its distribution should be harmless. Many varieties of commercial infant formula were distributed by a variety of agencies, often with foreign labelling and no instruction or counselling on usage. Similar widespread distribution of BMS has been observed after many recent natural disasters including the Indian Ocean tsunami in $2004^{(35)}$, Pakistan earthquake in $2005^{(36)}$, Bangladesh cyclone in $2007^{(37)}$, Philippines typhoon in $2007^{(38)}$ and China earthquake in $2008^{(39,40)}$. A rapid search on the Internet in late January 2010 again revealed calls for donations of infant formula for the victims of the earthquake in Haiti. Clearly, health authorities in Indonesia and elsewhere, supported by local and international technical and professional agencies, must raise awareness among relief and philanthropic agencies on this issue.

On the basis of similar observations in Aceh after the 2004 tsunami, in 2005 UNICEF, WHO and the Indonesian Paediatric Association released a joint statement on Infant Feeding in Emergencies, followed by a related policy note from the Ministry of Health. Both were distributed to all province health offices. Although this was apparently ignored in the immediate aftermath of this disaster, the findings of this survey had an impact. The data were used to facilitate advocacy and promotion of appropriate IYCF in Yogyakarta and Central Java. However, it became clear that this was insufficient. Accordingly, UNICEF and the Indonesia Ministry of Health initiated a 'cascade' programme to train local breast-feeding counsellors. Involvement of the government and a local women's empowerment group elevated IYCF to the highest level of the humanitarian agenda, and since 2006 a stronger national commitment to good IYCF practices has been shown. The related initiatives ${ }^{(41)}$ are relevant to both routine infant care and to future natural disasters. During the September 2009 West Java and West Sumatera earthquakes, IYCF responses had improved. Humanitarian actors had apparently started to consider the principles in the Operational Guidance in their responses, and the government removed infant formula from the ration distributed to affected families ${ }^{(42)}$. Informal reports also indicated a strong local government commitment to containing and managing the BMS donations received.

Uncontrolled distribution of infant formula and other BMS can be extremely efficient during humanitarian emergencies, but, as documented clearly here, is bad for the health of children. It is encouraging that so many actors want to help, and particularly that they are concerned to help the most vulnerable - infants and young children. However, relief agencies are often inexperienced and poorly supervised in what is often a chaotic situation. The unregulated relief, donor and philanthropic environment that prevails in most humanitarian emergencies has the potential to cause great harm; the assistance provided, including BMS, should be regulated appropriately. This is beginning to happen in Indonesia. Further research is needed to determine why and by whom BMS continues to be distributed during emergencies elsewhere, and how this can be discouraged.

\section{Acknowledgements}

The fieldwork described in this paper was funded by UNI$\mathrm{CEF}$ Indonesia. Follow-up analysis and writing were undertaken independently by the authors. The authors declare no conflict of interest, and they have all seen and approved the 
content of the paper. The views expressed in this paper are solely attributable to the authors, and not to UNICEF globally or to any of the UNICEF Country Offices where they work. The present paper presents original work and analysis undertaken by the authors. Approval from the Institutional Review Board was not required by the implementing agencies as identifying data were not maintained and the research was a passive assessment of the situation with no intervention by the survey team. Some of the basic results were presented in a non peer-reviewed online bulletin cited as reference 41 . The focus of this earlier description of the work was mostly on the follow-up to the survey and only descriptive analysis was documented in that report. D.B.H. managed the team undertaking the survey, further designed and assisted with the data analysis and wrote the paper; F.A., A.W. and S.S. conceived and facilitated implementation of the survey; F.A. contributed to writing the original survey report; S.S. analysed the survey data, drafted the manuscript and assisted with its finalisation. The authors recognise and thank Ms Dorothy Foote and Mr Agus Riyanto, consultants to UNICEF Indonesia in June 2006, for their contribution to the design and conduct of the survey described in the present paper, and also the staff and students at the University of Gajah Mada School of Public Health for their work in the field. The authors also thank Professor Damien Jolley of Monash University, Australia, and Drs France Begin and William Hawley and Ms Lilian Selenje of UNICEF for their helpful comments on the analysis and manuscript.

\section{References}

1. Anonymous (2006) Walhi: 83 Persen Wilayah Indonesia Rawan Bencana. http://www.antara.co.id/arc/2006/12/27/ walhi-83-persen-wilayah-indonesia-rawan-bencana/ (accessed September 2010).

2. World Health Organization (2006) Earthquake, Yogyakarta and Central Java. Emergency Situation Report no. 1. Geneva: WHO; available at http://www.who.or.id/eng/ $\mathrm{php} /$ content/jogja-centraljava/Sitrep\%20Indonesia\%20JogjaCentral\%20Java\%2029-05-06\%20(1).pdf

3. World Health Organization (2006) Yogyakarta and Central Java Earthquake. Situation Report no. 7. Geneva: WHO; available at http://www.who.or.id/eng/php/content/jogjacentraljava/Sitrep\%20Indonesia\%20Jogja-Central\%20Java\% 2004-06-06\%20(7).pdf

4. IFE Core Group (2007) Infant and Young Child Feeding in Emergencies. Operational Guidance for Emergency Relief Staff and Programme Managers. Oxford: IFE Core Group c/o Emergency Nutrition Network; available at http://www. ennonline.net/pool/files/ife/ops-guidance-2-1-english-010307with-addendum.pdf

5. Herman A, Kusumastuti E, Bayu et al. (2006) Muba Kirim Langsung: Bantuan ke Bantul. http://www.suarakaryaonline.com/news.html?id=145232 (accessed September 2010).

6. UNICEF (2009) Tracking Progress on Child and Maternal Nutrition. New York: UNICEF.

7. World Health Organization, UNICEF \& Wellstart International (2009) Baby-friendly Hospital Initiative: Revised, Updated and Expanded for Integrated Care. Section 3: Breastfeeding Promotion and Support in a Baby-friendly Hospital. A 20-Hour Course for Maternity Staff. Geneva: WHO.
8. Statistics Indonesia (Badan Pusat Statistik - BPS) \& Macro International (2008) Indonesia Demographic and Health Survey 2007. Calverton, MD: BPS and Macro International.

9. Jones G, Steketee RW, Black RE et al. (2003) How many child deaths can we prevent this year? Lancet 362, 65-71.

10. Kovar MG, Serdula MK, Marks JS et al. (1984) Review of the epidemiologic evidence for an association between infant feeding and infant health. Pediatrics 74, Pt 2, 615-638.

11. Jason JM, Nieburg P \& Marks JS (1984) Mortality and infectious disease associated with infant-feeding practices in developing countries. Pediatrics 74, Pt 2, 702-727.

12. Victora CG, Smith PG, Vaughan JP et al. (1987) Evidence for protection by breast-feeding against infant deaths from infectious diseases in Brazil. Lancet 2, 319-322.

13. Rubin DH, Leventhal JM, Krasilnikoff PA et al. (1990) Relationship between infant feeding and infectious illness: a prospective study of infants during the first year of life. Pediatrics 85, 464-471.

14. Howie PW, Forsyth JS, Ogston SA et al. (1990) Protective effect of breast feeding against infection. BMJ 300, 11-16.

15. Beaudry M, Dufour R \& Marcoux S (1995) Relation between infant feeding and infections during the first six months of life. J Pediatr 126, 191-197.

16. Toole MJ \& Waldman RJ (1997) The public health aspects of complex emergencies and refugee situations. Annu Rev Public Health 18, 283-312.

17. Anonymous (2006) Diarrhoea Risk Associated with Not Breastfeeding in Botswana. Report no. 29. Oxford: Emergency Nutrition Network; available at http://fex. ennonline.net/29/diarrhoearisk.aspx

18. Gribble K (2005) Infant feeding in the post Indian Ocean tsunami context: reports, theory and action. Birth Issues 14, 121-127.

19. World Health Organization (1991) Indicators for Assessing Breastfeeding Practices. Geneva: WHO.

20. Nutrition and Health Surveillance System Indonesia (2004) Indonesia Crisis Bulletin: Nutrition and Health Surveillance in Rural Central Java - Key Results for the Period: December 1999-September 2003. Jakarta Pusat: Helen Keller International, Indonesia Country Office; available at http://www. hki.org/research/Ind\%20Cris\%20Bul\%20y5\%20iss\%2010.pdf

21. Anonymous (2006) Aid for Java earthquake underway: relief organizations and Swiss solidarity provide CHF 1 million. https://www.swiss-solidarity.org/Java.290.0.html? $\& \mathrm{~L}=3 \& \mathrm{tx} \_\mathrm{ttnews} \% 5 \mathrm{Btt} \_$news $\% 5 \mathrm{D}=2269 \mathrm{\& tx}$ _ttnews $\% 5 \mathrm{Bback}$ $\mathrm{Pid} \% 5 \mathrm{D}=288 \& \mathrm{cHash}=54600260 \mathrm{a}$ (accessed September 2010).

22. Wiebe G (2006) Yogyakarta earthquake response update. http://ocha-gwapps1.unog.ch/rw/rwb.nsf/db900SID/SODA6SF8V7?OpenDocument (accessed September 2010).

23. Coolen E (2006) Yogyakarta earthquake. Jesuit Refugee Service Indonesia. http://www.jrs.or.id/index.php?option= com_content\&task $=$ view\&id $=46 \& I t e m i d=117 \quad$ (accessed September 2010)

24. Aarts C, Kylberg E, Hornell A et al. (2000) How exclusive is exclusive breastfeeding? A comparison of data since birth with current status data. Int J Epidemiol 29, 1041-1046.

25. UNICEF (2008) The State of the World's Children 2008. New York: UNICEF.

26. Assefa F, Jabarkhil MZ, Salama P et al. (2001) Malnutrition and mortality in Kohistan district, Afghanistan, April 2001. JAMA 286, 2723-2728.

27. Salama P, Assefa F, Talley L et al. (2001) Malnutrition, measles, mortality, and the humanitarian response during a famine in Ethiopia. JAMA 286, 563-571.

28. Creek T, Arvelo W, Kim L et al. (2007) Role of infant feeding and HIV in a severe outbreak of diarrhea and malnutrition among young children, Botswana, 2006. Presented at CROI 2007, 14th Conference of Retroviruses and Opportunistic Infections, Los Angeles, CA, 25-28 February 2007 [abstract 770]. 
29. Leon-Cava N, Lutta C, Ross J et al. (2002) Quantifying the Benefits of Breastfeeding: A Summary of the Evidence. Washington, DC: PAHO

30. Paricio Talayero JM, Lizan-Garcia M, Otero PA et al. (2006) Full breastfeeding and hospitalization as a result of infections in the first year of life. Pediatrics 118, e92-e99.

31. Dewey KG, Heinig MJ \& Nommsen-Rivers LA (1995) Differences in morbidity between breast-fed and formulafed infants. J Pediatr 126, Pt 1, 696-702.

32. Horta B, Bahl R, Martines J et al. (2007) Evidence on the Long-term Effects of Breastfeeding: Systematic Reviews and Meta-analyses. Geneva: WHO.

33. World Health Organization (2005) Guiding Principles for Feeding Non-breastfed Children Aged 6-24 months. Geneva: WHO.

34. World Health Organization (1981) The International Code of Marketing of Breast-milk Substitutes. Geneva: WHO.

35. Anonymous (2005) Bright Beginnings(TM), the infant formula endorsed by Brooke Shields, donates infant formula and pediatric nutritional drinks to victims of the Indian Ocean tsunami. http://www2.prnewswire.com/cgibin/stories.pl?ACCT = 105\&STORY=/www/story/01-25-2005/ 0002902203 (accessed September 2010).

36. Arts M (2006) Infant feeding in the South Asia earthquake aftermath. http://fex.ennonline.net/pdf/27.pdf (accessed September 2010).
37. Maclaine A (2008) Infant and young child feeding in emergencies in selected unions affected by Cyclone Sidr. http://fex.ennonline.net/29/infantfeeding.aspx (accessed September 2010)

38. Anonymous (2007) Philippines: Nestlé donates nutritional formula to Red Cross for victims of recent typhoons. http://ocha-gwapps1.unog.ch/rw/rwb.nsf/db900SID/JBRN6Y2F7E? OpenDocument (accessed September 2010).

39. Pang Li (2008) Donations: milk powder and diapers greatly needed in quake-hit areas (China). http://www. ennonline.net/resources/view.aspx?resid=635 (accessed September 2010)

40. Anonymous (2008) Hongkong earthquake aid tied up in red tape. http://www.earthtimes.org/articles/show/220791, hong-kong-earthquake-aid-tied-up-in-red-tape.html (accessed May 2010).

41. Assefa F, Sukotjo S, Winoto A et al. (2008) Increased Diarrboea Following Infant Formula Distribution in 2006 Earthquake Response in Indonesia: Evidence and Actions. Report no. 34. Oxford, UK: Emergency Nutrition Network; available at http://fex.ennonline.net/34/special.aspx

42. Departemen Sosial RI (2009) Laporan Penanggulangan Bencana Gempa Bumi di Provinsi Sumatera Barat. Indonesia: Departemen Sosial Republik Indonesia. 